\title{
Osteomalacia secondary to renal tubular acidosis due to Sjögren's syndrome: a case report and review of the literature
}

\author{
Hiroshi Nagae $\cdot$ Yuko Noguchi $\cdot$ Shinako Ogata \\ Chinami Ogata $\cdot$ Rei Matsui $\cdot$ Yukiko Shimomura \\ Ritsuko Katafuchi
}

Received: 7 February 2012 / Accepted: 22 June 2012/Published online: 15 August 2012

(C) Japanese Society of Nephrology 2012

\begin{abstract}
A 43-year-old woman was admitted to our hospital because of generalized bone pain. Arterial blood gas showed $\mathrm{pH} 7.266, \mathrm{HCO}_{3}{ }^{-} 13.5 \mathrm{mEq} / \mathrm{l}$, and anion gap (AG) 12. Since her urine $\mathrm{pH}$ was 7.0 despite metabolic acidosis with normal AG, we diagnosed distal renal tubular acidosis (RTA). Serum phosphate was $2.5 \mathrm{mg} / \mathrm{dl}$, the level of $\beta 2$ microglobulin was $41100 \mu \mathrm{g} / \mathrm{l}$, and aminoaciduria was present. These results indicated proximal tubular dysfunction. The radiograph showed pseudofracture in the pubic bone, indicating osteomalacia. Bone scintigram showed abnormal accumulations of 99mTc-HMDP in multiple joints. Then, her generalized bone pain was considered to be a symptom of osteomalacia. Despite the absence of overt Sicca syndrome, the evaluation of Sjögren's syndrome $(\mathrm{SjS})$ as a cause of distal RTA was performed. Antibodies to the SS-A level was $127 \mathrm{U} / \mathrm{ml}$. Tear break-up time was $3 \mathrm{~s}$ bilaterally and salivary gland scintigraphy showed low uptake of $99 \mathrm{mTc}$ in the submandibular glands and the parotids. Thus, we diagnosed SjS finally. Gallium scintigraphy showed mild abnormal uptake in bilateral kidneys, suggesting acute tubulointerstitial nephritis. After treatment with prednisolone, alfacalcidol, and sodium bicarbonate, bone pain was remarkably relieved. Additionally, aminoaciduria disappeared and the level of $\beta 2$ microglobulin decreased. We speculated that the coincidence of proximal tubular dysfunction and distal RTA cause a severe manifestation of osteomalacia.
\end{abstract}

H. Nagae $(\bowtie) \cdot$ Y. Noguchi $\cdot$ S. Ogata $\cdot$ C. Ogata · R. Matsui Y. Shimomura $\cdot$ R. Katafuchi

National Fukuoka Higashi Medical Center, Chidori, Koga,

Fukuoka 811-3113, Japan

e-mail: vutakim@hotmail.com
Keywords Osteomalacia - Renal tubular acidosis · Sjögren's syndrome

\section{Introduction}

Sjögren's syndrome $(\mathrm{SjS})$ is a chronic inflammatory disorder affecting lacrimal and salivary gland function. It is a systemic disease, with manifestations from several organ systems, such as lung, skin, gastrointestinal tract, central and peripheral nervous system, muscles, and the kidney [1]. Renal involvement, such as tubulointerstitial nephritis, renal tubular acidosis (RTA), and glomerular disease, may occur as an extraglandular manifestation of $\mathrm{SjS}$ [2]. Although RTA is one of the causes of osteomalacia [3], only a few case reports of osteomalacia with $\mathrm{SjS}$ have been published. Here, we report a case diagnosed as osteomalacia associated with $\mathrm{SjS}$ and reviewed the literature.

\section{Case report}

A 43-year-old woman was admitted to our hospital in August 2010 because of generalized bone pain. She had developed right chest pain and back pain, without antecedents, at age 42 years. At that time, she was diagnosed as right rib fracture and vertebral fracture, and was administered non-steroidal anti-inflammatory drugs. Thereafter, her symptoms worsened and she had developed left ankle pain. No other family members had osteomalacia or bone metabolic diseases. She had no history of malabsorption, short stature, or limb deformity. She had been taking no drugs or metals that might have caused RTA or osteomalacia.

Her height, body weight, and body mass index were $150 \mathrm{~cm}, 43.0 \mathrm{~kg}$, and $19.1 \mathrm{~kg} / \mathrm{m}^{2}$, respectively. Her blood 
pressure was $118 / 64 \mathrm{mmHg}$, pulse rate was 76 beats/min, and body temperature was 36.6. Physical examination was not remarkable except for the pain in her ribs, back, and left ankle.

Complete blood count showed white blood cell count $4.3 \times 10^{3} / \mu \mathrm{l} \quad\left(4.3 \times 10^{9} / \mathrm{l}\right)$ and hemoglobin $14.1 \mathrm{~g} / \mathrm{dl}$ $(141 \mathrm{~g} / \mathrm{l})$. Blood chemistry showed blood urea nitrogen $14.2 \mathrm{mg} / \mathrm{dl}(5.1 \mathrm{mmol} / \mathrm{l})$, creatinine $0.8 \mathrm{mg} / \mathrm{dl}(70.7 \mu \mathrm{mol} /$ 1), sodium $143 \mathrm{mEq} / 1$ (143 mmol/l), potassium $2.8 \mathrm{mEq} / \mathrm{l}$ ( $2.8 \mathrm{mmol} / \mathrm{l})$, chloride $117 \mathrm{mEq} / \mathrm{l}(117 \mathrm{mmol} / \mathrm{l})$, calcium $9.3 \mathrm{mg} / \mathrm{dl}(2.3 \mathrm{mmol} / \mathrm{l})$, phosphate $2.5 \mathrm{mg} / \mathrm{dl}(0.8 \mathrm{mmol} / \mathrm{l})$, uric acid $2.9 \mathrm{mg} / \mathrm{dl}(172.5 \mu \mathrm{mol} / \mathrm{l})$, albumin $4.2 \mathrm{~g} / \mathrm{dl}(42$ g/l), and alkaline phosphatase (ALP) 897 U/l: ALP2 $29 \%$, ALP3 $71 \%$. Arterial blood gas showed $\mathrm{pH} 7.266, \mathrm{pO}_{2}$ $116 \mathrm{mmHg}, \quad \mathrm{PCO}_{2} \quad 30 \mathrm{mmHg}, \quad \mathrm{HCO}_{3}{ }^{-} \quad 13.5 \mathrm{mEq} / \mathrm{l}$ (13.5 mmol/l), and anion gap (AG) $12 \mathrm{mEq} / \mathrm{l}(12 \mathrm{mmol} / \mathrm{l})$. Urinalysis showed $\mathrm{pH}$ 7.0, no proteinuria, no hematuria, and no glycosuria, and the urinary sediment was not significant. A diagnosis of distal RTA was made because her urine showed alkalinity, despite severe metabolic acidosis with normal AG. The level of urinary excretion of $\beta 2$ microglobulin was $41100 \mu \mathrm{g} / \mathrm{l}$ and aminoaciduria was present. The percentage of tubular reabsorption of phosphate (\%TRP) was $70 \%$. Therefore, proximal tubular dysfunction was evident. Serum intact parathyroid hormone level was $25.6 \mathrm{pg} / \mathrm{ml}(25.6 \mathrm{ng} / \mathrm{l}$, normal $10-65$ $\mathrm{pg} / \mathrm{ml}), 25$-dihydroxyvitamin D was $11.6 \mathrm{ng} / \mathrm{ml}(29.0 \mathrm{nmol} / \mathrm{l}$, normal $9.0-33.9 \mathrm{ng} / \mathrm{ml}$ ), and 1,25-dihydroxyvitamin $\mathrm{D}$ was $15 \mathrm{pg} / \mathrm{ml}$ (39 pmol/1, normal $20-60 \mathrm{pg} / \mathrm{ml})$. There was bilateral nephrocalcinosis on plain abdominal radiography, abdominal echography, and computed tomography. The radiograph of the pelvis showed pseudofracture, i.e., Looser's zone, in the pubic bone, which indicated osteomalacia (Fig. 1). Bone scintigram showed abnormal accumulations of $99 \mathrm{mTc}-\mathrm{HMDP}$ in the left clavicle, bilateral ribs, L4 spine, pelvis, and left ankle. After examinations of whole-body computed tomography, gastrointestinal endoscopy, colonoscopy, and mammography, bone metastases of malignancy were excluded. Gallium (Ga) scintigraphy showed mild abnormal uptake in bilateral kidneys, left articulatio sternoclavicularis, left inguinal lesion, and left ankle. The uptake of Ga-citrate in the kidney suggested tubulointerstitial nephritis (Fig. 2). A test of antinuclear antibodies was positive in a titer of $1: 160$ with a speckled pattern; the level of antibodies to SS-A was $127 \mathrm{U} / \mathrm{ml}$ (normal 0-30 U/ml) and SS-B was negative. Tear break-up time was $3 \mathrm{~s}$ bilaterally. Salivary gland scintigraphy revealed low uptake in the submandibular glands and the parotids. According to the clinical findings and laboratory data, she was diagnosed as osteomalacia and $\mathrm{SjS}$.

The clinical course is shown in Fig. 3. The administration of $0.25 \mu \mathrm{g}$ alfacalcidol and $3 \mathrm{~g}$ sodium bicarbonate was started, in order to treat osteomalacia. One month later, serum phosphate elevated to $3.7 \mathrm{mg} / \mathrm{dl}$. However, generalized bone pain diminished partially. Six months later, $30 \mathrm{mg}$ prednisolone was additionally administrated. Her symptom promptly ameliorated thereafter. Seven months after treatment, serum ALP was normalized and 1 year after treatment, aminoaciduria disappeared. \%TRP also improved to $84 \%$.

Fig. 1 Radiograph of the pelvis. The arrows show pseudofracture in the pubic bone

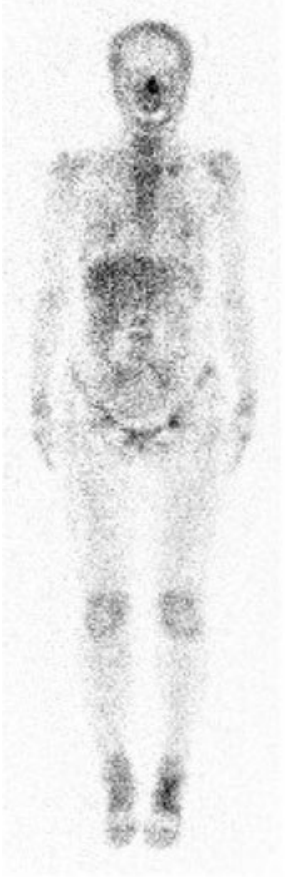

ANT

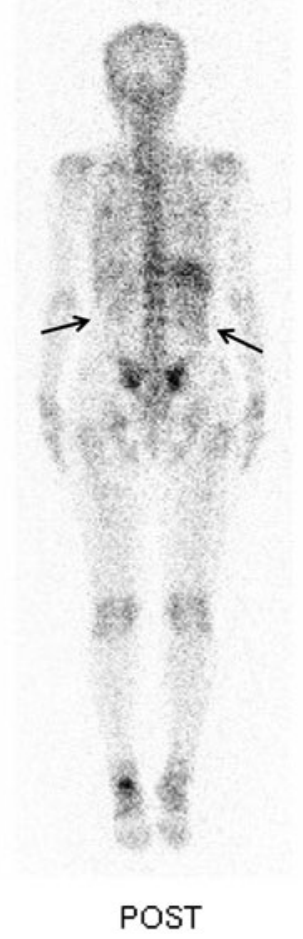

POST
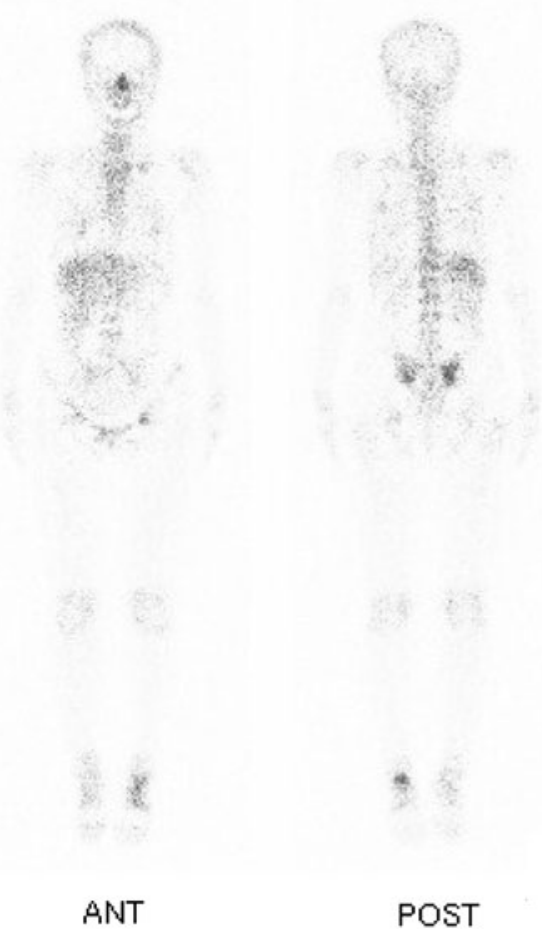


\section{Discussion}

We reported a case of osteomalacia secondary to distal RTA due to SjS. In our case, the existence of distal RTA was definite because of constant high urine $\mathrm{pH}$ in spite of severe acidemia. Nephrocalcinosis was compatible with distal RTA. Since the patient's main symptom was generalized bone pain rather than Sicca syndrome, it was very difficult to make a diagnosis of $\mathrm{SjS}$. It took about 1 month to make the final diagnosis of $\mathrm{SjS}$.

Osteomalacia has been rarely reported in $\mathrm{SjS}$ patients. Since the first report [14] of the case of SjS with osteomalacia was published in 1977, as far as we investigated, only 13 cases have been reported in English and Japanese so far [4-16]. Previous published case reports are summarized in Table 1 . The median age was 41 years, ranging

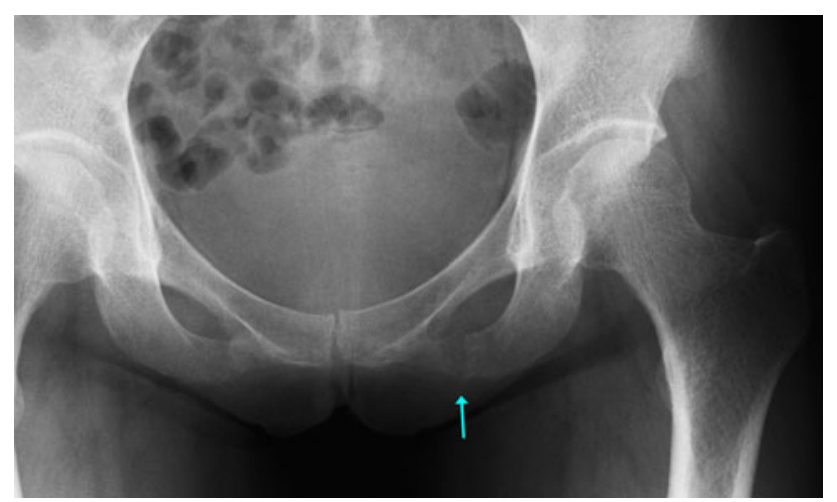

Fig. 2 Gallium scintigraphy. Mild uptake of Ga-citrate was observed in bilateral kidneys (arrow), left articulatio sternoclavicularis, left inguinal lesion, and left ankle from 30 to 71 years, and all cases were women. Osteomalacia was the first manifestation of $\mathrm{SjS}$ in seven cases. All cases of osteomalacia with $\mathrm{SjS}$ developed distal RTA and two patients developed mixed distal and proximal RTA $[11,16]$, confirmed by the sodium bicarbonate loading test. The other eight patients [4, 6-10, 12, 13] showed evidence of proximal tubular dysfunction, such as aminoaciduria, renal glycosuria, hypophosphatemia, hypouricemia, or a high level of urinary excretion of $\beta 2$ microglobulin.

Distal RTA is characterized by impaired distal acid secretory capacity. This defect leads to an inability to excrete the daily acid load, resulting in progressive hydrogen ion retention and a decrease in plasma bicarbonate concentration. The diagnosis of distal RTA is made by the presence of alkaline urine under metabolic acidosis with normal AG. Causes of distal RTA in adults include hypercalciuria and autoimmune diseases, such as $\mathrm{SjS}$ and rheumatoid arthritis [17]. Although distal RTA is reported to occur in 11-30\% of patients with $\mathrm{SjS}[2,18]$, the mechanism of distal RTA in SjS is not fully understood. Since urinary acidification in the collecting tubules is achieved via $\mathrm{H}^{+}$secretion by a luminal $\mathrm{H}^{+}$-ATPase pump, diminished $\mathrm{H}^{+}$-ATPase activity is thought to be one of the causes of distal RTA [19]. Cohen et al. [20] reported that an absence of $\mathrm{H}^{+}$-ATPase in the cortical collecting tubules was observed in the kidney biopsy specimen of a patient with distal RTA with SjS. Fulop and Mackay [12] documented that there seemed to be no better explanation for the bone disease in $\mathrm{SjS}$ than some combination of acidosis and hypophosphatemia. Coexisting vitamin D deficiency, when present, may be an aggravating factor. In our case, metabolic acidosis, hypophosphatemia, and vitamin D deficiency existed. Thus, osteomalacia in our
Fig. 3 Clinical course. Administration of alfacalcidol and sodium bicarbonate were started in order to treat osteomalacia and 6 months after prednisolone was added. Bone pain ameliorated and serum alkaline phosphatase (ALP) normalized

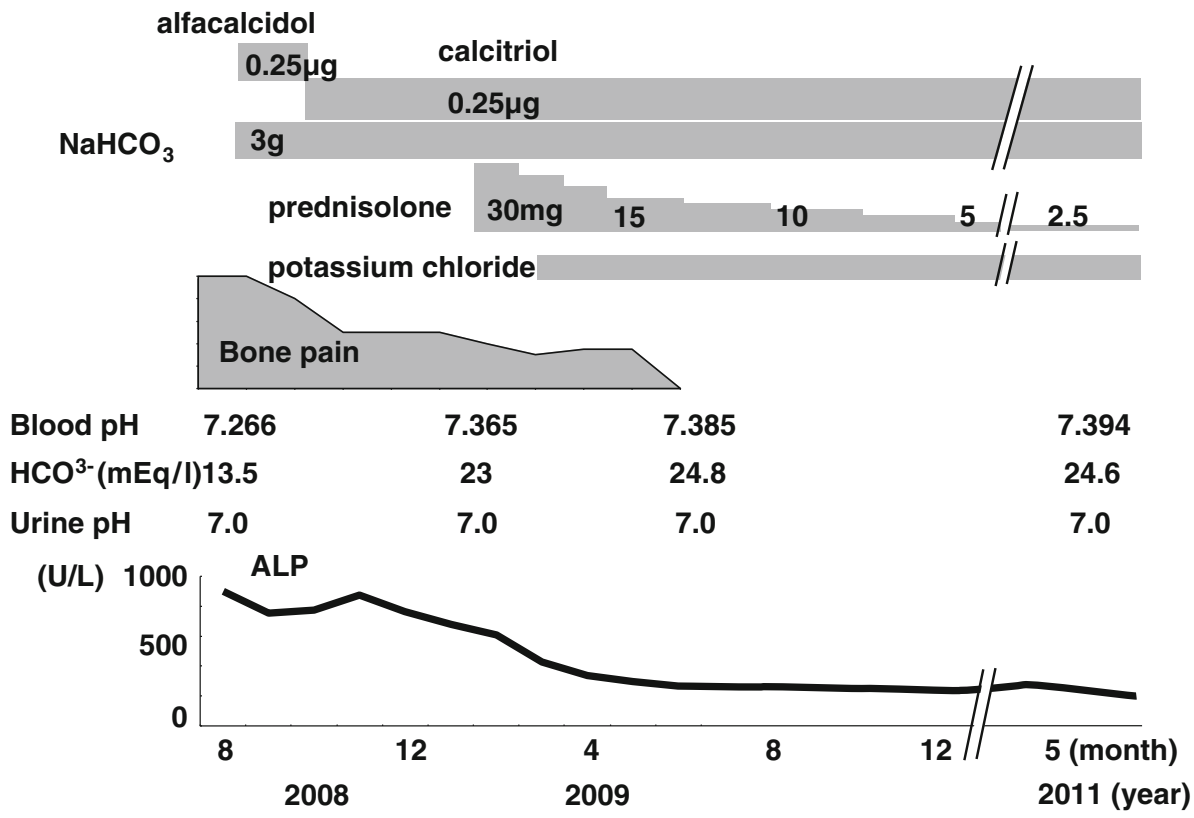




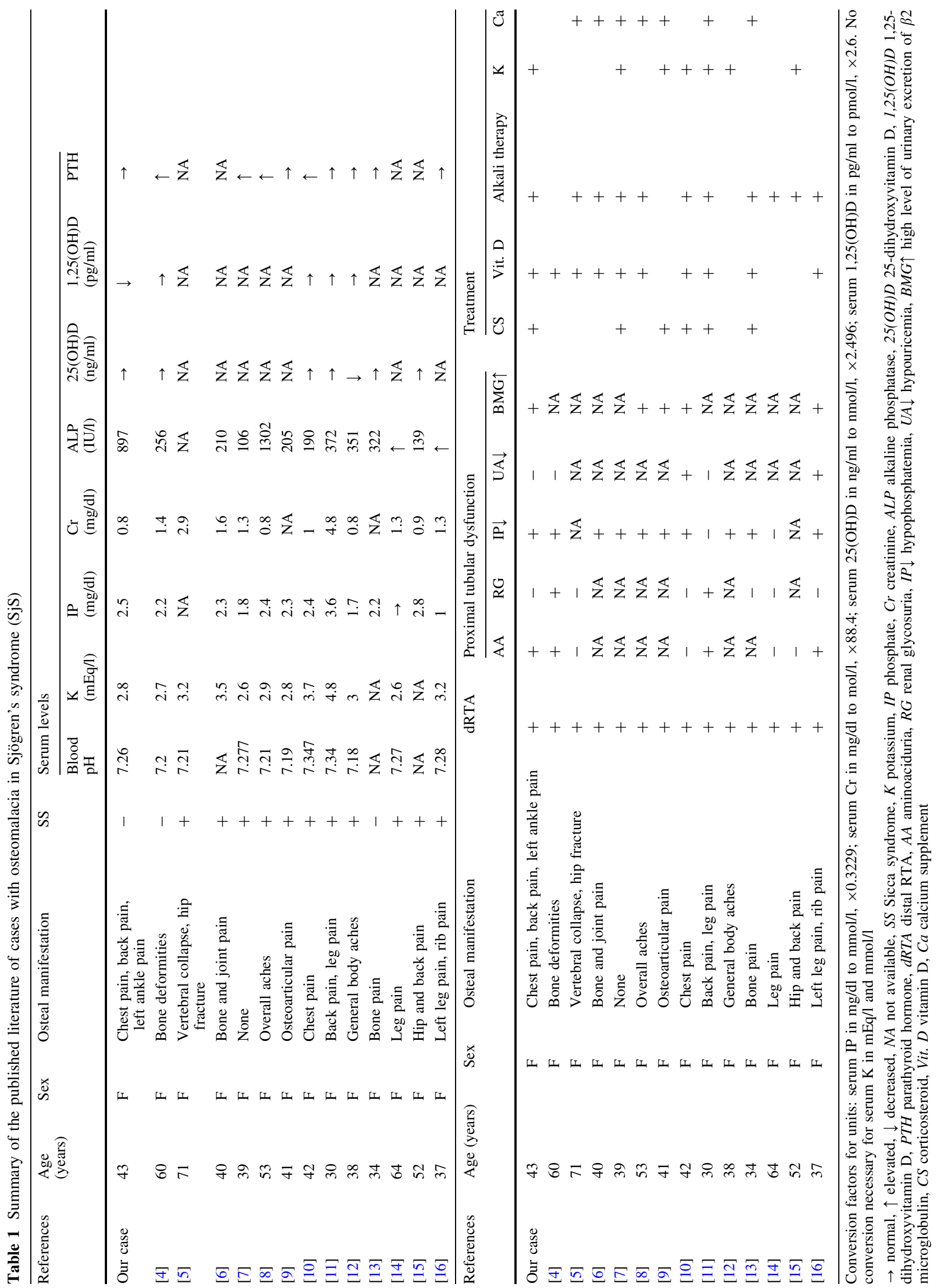


case might be explained by distal RTA alone. However, if so, why were there only 13 cases that developed osteomalacia associated with $\mathrm{SjS}$ ?

Proximal RTA is a well-known cause of osteomalacia [3]. This fact may be due, in part, to phosphate wasting and subsequent hypophosphatemia and to acquired vitamin D deficiency, since the proximal tubule is a major site of formation of activated vitamin D. Additionally, acidemia can directly decrease in bone mineralization. The causes of proximal RTA in adults include multiple myeloma, hypocalcemia, drugs, heavy metals, amyloidosis, renal transplant rejection, or $\mathrm{SjS}$ [19]. As mentioned above, 10 out of 13 cases of osteomalacia with $\mathrm{SjS}$ developed proximal tubular dysfunction or proximal RTA in addition to distal RTA. We speculated that the aggravation of decrease in bone mineralization due to proximal tubular dysfunction, as well as distal RTA, seemed to cause a severe manifestation of osteomalacia in our case.

Tubulointerstitial nephritis might be a causative factor for RTA in SjS. In the review of the literature, renal biopsy was performed for five out of 13 cases and all biopsy specimens showed tubulointerstitial nephritis. We tried to perform renal biopsy in this patient. However, this was not possible because of severe generalized bone pain. She could not even lie on her stomach. Ga-citrate uptake in both kidneys was compatible with tubulointerstitial nephritis. At first, we administrated alfacalcidol and sodium bicarbonate, but its effect on bone pain was limited. Thus, we decided to use prednisolone for the treatment of underlying $\mathrm{SjS}$. After the administration of prednisolone, the bone pain almost completely disappeared. We speculated that prednisolone ameliorated tubulointerstitial nephritis in $\mathrm{SjS}$, resulting in improvement of tubular function. In fact, laboratory abnormalities indicating proximal tubular dysfunction such as aminoaciduria, hypophosphatemia, and high level of urinary excretion of $\beta 2$ microglobulin improved and, concurrently, bone pain relieved.

We report a case of osteomalacia secondary to distal RTA due to SjS. Even in the absence of overt Sicca syndrome, $\mathrm{SjS}$ should be considered as one of the causal diseases in the patient presenting generalized bone pain.

\section{Conflict of interest None.}

\section{References}

1. Asmussen K, Andersen V, Bendixen G, Schiødt M, Oxholm P. A new model for classification of disease manifestations in primary Sjögren's syndrome: evaluation in a retrospective long-term study. J Intern Med. 1996;239:475-82.

2. Aasarød K, Haga HJ, Berg KJ, Hammerstrøm J, Jørstad S. Renal involvement in primary Sjögren's syndrome. QJM. 2000;93: 297-304.
3. Brenner RJ, Spring DB, Sebastian A, McSherry EM, Genant HK, Palubinskas AJ, et al. Incidence of radiographically evident bone disease, nephrocalcinosis, and nephrolithiasis in various types of renal tubular acidosis. N Engl J Med. 1982;307:217-21.

4. Yang YS, Peng CH, Sia SK, Huang CN. Acquired hypophosphatemia osteomalacia associated with Fanconi's syndrome in Sjögren's syndrome. Rheumatol Int. 2007;27:593-7.

5. Díaz Rodríguez C, González Rivero C, Trinidad San José JC, Del Río Romero D, Moreno Fernández A, Granja Romero E. Osteal complications as first manifestation in a patient with primary Sjögren's syndrome and with associated distal tubular acidosis (type 1) and chronic renal insufficiency. Ther Apher Dial. 2004;8:160-3.

6. Hajjaj-Hassouni N, Guedira N, Lazrak N, Hassouni F, Filali A, Mansouri A, et al. Osteomalacia as a presenting manifestation of Sjögren's syndrome. Rev Rhum Engl Ed. 1995;62:529-32.

7. Kawashima M, Amano T, Morita Y, Yamamura M, Makino H. Hypokalemic paralysis and osteomalacia secondary to renal tubular acidosis in a case with primary Sjögren's syndrome. Mod Rheumatol. 2006;16:48-51.

8. Okada M, Suzuki K, Hidaka T, Shinohara T, Kataharada K, Matsumoto M, et al. Rapid improvement of osteomalacia by treatment in a case with Sjögren's syndrome, rheumatoid arthritis and renal tubular acidosis type 1. Intern Med. 2001;40: 829-32.

9. Monte Neto JT, Sesso R, Kirsztajn GM, Da Silva LC, De Carvalho AB, Pereira AB. Osteomalacia secondary to renal tubular acidosis in a patient with primary Sjögren's syndrome. Clin Exp Rheumatol. 1991;9:625-7.

10. Okazaki H, Muto S, Kanai N, Shimizu H, Masuyama J, Minato $\mathrm{N}$, et al. A case of primary Sjögren's syndrome presenting as osteomalacia secondary to renal tubular acidosis. Ryumachi. 1991;31:45-53.

11. Haba T, Takahashi K, Kito C, Akashi N, Yamazaki Y, Saito K. A case of Sjogren syndrome with renal tubular acidosis, osteomalacia and pseudo-bone fracture. Nihon Naika Gakkai Zasshi. 1994;83:127-9.

12. Fulop M, Mackay M. Renal tubular acidosis, Sjögren syndrome, and bone disease. Arch Intern Med. 2004;164:905-9.

13. Saoud B, Bahiri R, Benbouazza K, Bzami F, Guedira N, HajjajHassouni N. Osteomalacia revealing Sjogren's syndrome. Joint Bone Spine. 2005;72:594-5.

14. Marquez-Julio A, Rapoport A, Wilansky DL, Rabinovich S, Chamberlain D. Purpura associated with hypergammaglobulinemia, renal tubular acidosis and osteomalacia. Can Med Assoc J. 1977;116:53-8.

15. Pal B, Griffiths ID. Primary Sjogren's syndrome presenting as osteomalacia secondary to renal tubular acidosis. Br J Clin Pract. 1988;42:436-8.

16. Hoshina H, Akaboshi T, Kato K, Mishina T, Kashiwazaki S. A case of Sjögren's syndrome with pseudofracture. Ryumachi. 1983;23:42-9.

17. Caruana RJ, Buckalew VM Jr. The syndrome of distal (type 1) renal tubular acidosis. Clinical and laboratory findings in 58 cases. Medicine (Baltimore). 1988;67:84-99.

18. Shioji R, Furuyama T, Onodera S, Saito H, Ito H, Sasaki Y. Sjögren's syndrome and renal tubular acidosis. Am J Med. 1970;48:456-63.

19. Rose BD, Post TW. Metabolic acidosis. In: Rose BD, Post TW, editors. Clinical physiology of acid-base and electrolyte disorders. 5th ed. New York: McGraw-Hill; 2001. p. 578-646.

20. Cohen EP, Bastani B, Cohen MR, Kolner S, Hemken P, Gluck SL. Absence of $\mathrm{H}(+)$-ATPase in cortical collecting tubules of a patient with Sjogren's syndrome and distal renal tubular acidosis. J Am Soc Nephrol. 1992;3:264-71. 